\title{
Wet and Dry Atmospheric Depositions of Inorganic Nitrogen during Plant Growing Season in the Coastal Zone of Yellow River Delta
}

\author{
Junbao Yu, ${ }^{1}$ Kai Ning, ${ }^{1,2}$ Yunzhao Li, ${ }^{1,2}$ Siyao Du, ${ }^{3}$ Guangxuan Han, ${ }^{1}$ \\ Qinghui Xing, ${ }^{1,2}$ Huifeng Wu, ${ }^{1}$ Guangmei Wang, ${ }^{1}$ and Yongjun Gao ${ }^{4}$ \\ ${ }^{1}$ Key Laboratory of Coastal Zone Environmental Processes and Ecological Remediation, Yantai Institute of \\ Coastal Zone Research (YIC), Chinese Academy of Sciences (CAS) and Shandong Provincial Key Laboratory of \\ Coastal Zone Environmental Processes, YICCAS, Yantai 264003, China \\ ${ }^{2}$ University of Chinese Academy of Sciences, Beijing 100049, China \\ ${ }^{3}$ College of Environmental Science and Engineer, Ocean University of China, China \\ ${ }^{4}$ Department of Geosciences, University of Houston, Houston, TX 77204, USA
}

Correspondence should be addressed to Junbao Yu; junbao.yu@gmail.com

Received 22 February 2014; Revised 15 March 2014; Accepted 15 March 2014; Published 1 April 2014

Academic Editor: Hong-bo Shao

Copyright (C) 2014 Junbao Yu et al. This is an open access article distributed under the Creative Commons Attribution License, which permits unrestricted use, distribution, and reproduction in any medium, provided the original work is properly cited.

\begin{abstract}
The ecological problems caused by dry and wet deposition of atmospheric nitrogen have been widespread concern in the world. In this study, wet and dry atmospheric depositions were monitored in plant growing season in the coastal zone of the Yellow River Delta (YRD) using automatic sampling equipment. The results showed that $\mathrm{SO}_{4}{ }^{2-}$ and $\mathrm{Na}^{+}$were the predominant anion and cation, respectively, in both wet and dry atmospheric depositions. The total atmospheric nitrogen deposition was $\sim 2264.24 \mathrm{mg} \mathrm{m}^{-2}$, in which dry atmospheric nitrogen deposition was about 32.02\%. The highest values of dry and wet atmospheric nitrogen deposition appeared in May and August, respectively. In the studied area, $\mathrm{NO}_{3}{ }^{-}-\mathrm{N}$ was the main nitrogen form in dry deposition, while the predominant nitrogen in wet atmospheric deposition was $\mathrm{NH}_{4}{ }^{+}-\mathrm{N}$ with $\sim 56.51 \%$ of total wet atmospheric nitrogen deposition. The average monthly attribution rate of atmospheric deposition of $\mathrm{NO}_{3}{ }^{-}-\mathrm{N}$ and $\mathrm{NH}_{4}{ }^{+}-\mathrm{N}$ was $\sim 31.38 \%$ and $\sim 20.50 \%$ for the contents of $\mathrm{NO}_{3}{ }^{-}-\mathrm{N}$ and $\mathrm{NH}_{4}{ }^{+}-\mathrm{N}$ in $0-10 \mathrm{~cm}$ soil layer, respectively, suggested that the atmospheric nitrogen was one of main sources for soil nitrogen in coastal zone of the YRD.
\end{abstract}

\section{Introduction}

It is well known that nitrogen is an important nutrient in terrestrial and marine ecosystems. The primary production, the nutrient cycling, and the biodiversity in natural ecosystems were great limited by the availability of reactive nitrogen [1-5]. The global reactive nitrogen production rate increased from approximately $15 \mathrm{Tg} \mathrm{N} \mathrm{yr}^{-1}$ in 1860 to $187 \mathrm{Tg} \mathrm{N} \mathrm{yr}^{-1}$ in 2005; more than half of total was deposited onto the ground [6]. Atmospheric nitrogen deposition has become a large source of nitrogen for terrestrial and aquatic ecosystems worldwide [7]. The atmospheric nitrogen deposition can affect the soil nitrogen balance, which probably results in some negative effects on terrestrial and marine ecosystems
[8-10] through eutrophication and acidification [11]. Nitrogen entering the soil-plant system has been a main factor for the nitrogen cycle of ecosystem [12]. Atmospheric nitrogen deposition has frequently been observed to increase soil carbon (C) storage in natural ecosystems $[13,14]$. Some studies tried to build relations between atmospheric depositions and nitrogen concentration in moss and proved that mosses could serve as biological indicators for atmospheric nitrogen depositions [15]. Therefore, the atmospheric nitrogen deposition has become an increasingly important source for reactive nitrogen entering to the coastal ecosystems and contributed to the coastal nitrogen budget [5].

The ecological problems caused by dry and wet deposition of atmospheric nitrogen have widespread concern in the 


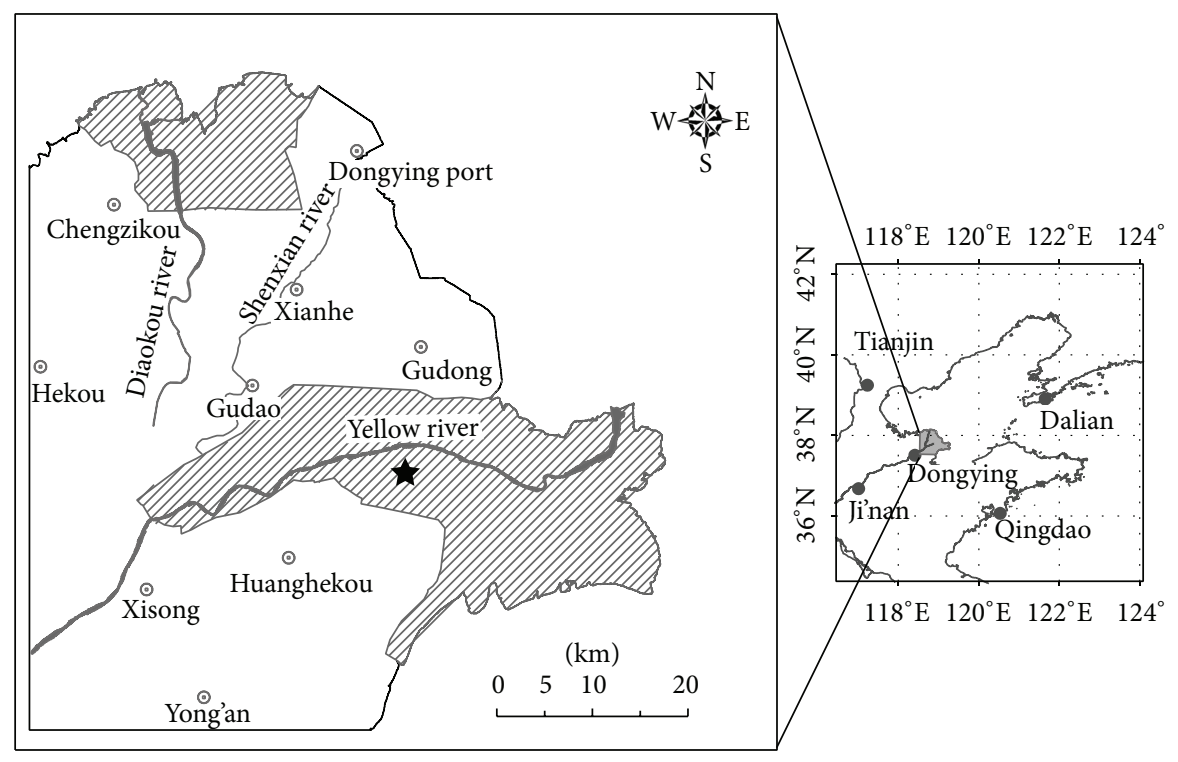

Sampling site

Yellow River Delta

National nature reserve

FIgure 1: The location of the Yellow River Delta and sampling sites.

world. In recent decades, high rates of atmospheric nitrogen deposition have been reported in Europe [16], East Asia [17], North America [18], and Northern and Southeastern China $[19,20]$. The National Atmospheric Deposition Program (NADP) was built to oversee the long-term sampling and analysis of precipitation across the United States, Puerto Rico, and the Virgin Islands [21], and the dry deposition was monitored by networks in Europe (EMEP), North America (CASTNET), and East Asia (EANET). As the largest developing country, China has consumed more than $24 \mathrm{Tg}_{\text {year }}{ }^{-1}$ fertilizer $\mathrm{N}$ in recent years, which is $\sim 30 \%$ of total fertilizer $\mathrm{N}$ used worldwide [22]. In addition, livestock production in China has increased greatly since the late 1980s. The amount of $\mathrm{NH}_{3}$ volatilization from wastes of domestic animals (manure and urine) is even higher than that from fertilizer use in China [23]. Furthermore, the transport network and traffic have increased rapidly since the 1980s in China, resulting in increasing $\mathrm{NO}_{x}$ emissions by $62 \%$ [24]. 70-80\% of the emitted nitrogen was deposited to the land or water surface as wet and dry deposition [11]. Nitrogen deposition was the highest over Southern China and exhibited a decreasing gradient from Southern to Western and Northern China. The anthropogenic activities were the main reason for the nitrogen deposition increase [25]. Therefore, China is now a hotspot for nitrogen deposition according to recent modeling studies [7, 25, 26]. However, the magnitude of atmospheric deposition of various $\mathrm{N}$ species in China remains uncertain because of a paucity of measurements and quantitative knowledge $[19,27]$. Previous studies of atmospheric nitrogen deposition in China have considered the wet and the dry deposition separately $[28,29]$ and most monitored locations were in agricultural areas and cities $[19,22]$. Few measurements have focused on both the wet and the dry deposition of individual nitrogen species in coastal wetlands. In this study, the dry and wet nitrogen deposition was monitored using automatic sampling equipment in coastal wetland of the Yellow River Delta (YRD) which is one of intensive agricultural regions and rapidly economic developing regions in China. The objectives of the present study were to (1) determine the composition and amount in dry and wet atmospheric nitrogen deposition, (2) reveal the monthly variation of nitrogen (wet/dry) deposition in growing season, and (3) assess the contribution of atmospheric nitrogen inputs to local soil.

\section{Materials and Methods}

2.1. Study Area Description. The sampling sites $\left(118^{\circ} 58^{\prime} \mathrm{E}\right.$, $37^{\circ} 45^{\prime} \mathrm{N}$ ) located at the Yellow River Delta Ecology Research Station of Coastal Wetland, Chinese Academy of Sciences (Figure 1), which is in the Yellow River DeltaNational Nature Reserve. All around the sampling sites was wide open without buildings. The climate in study area is warm temperate continental monsoon climate. It is arid and windy in spring, hot and rainy in summer, cool and sunny in autumn, and less snowy and dry in winter [30]. The annual average temperature is $\sim 12.1^{\circ} \mathrm{C}$, the annual average precipitation is $\sim 551.6 \mathrm{~mm}$, and the annual average evaporation is $\sim 1962 \mathrm{~mm}$. More than $85 \%$ of plants are the aquatic vegetation and halophytic vegetation in study region. The Suaeda salsa and Phragmites communis Trin are predominant plants and widely distributed [27]. 
2.2. Sampling. The dry and wet atmospheric depositions were monitored in plant growing season from May to November in 2012. The samples were collected using SCJ-302 model automatic sampling equipment (Qingdao Xuanhui Instruments \& Equipment Co. Ltd, China). The sensitivity of the equipment was $0.05 \mathrm{~mm} / \mathrm{h}$. The automatic sampling equipment stops the dry atmospheric deposition collection with a lid covered and starts to collect the wet atmospheric depositions sample within 60 seconds of rainfall event beginning. As soon as the precipitation ceased, the head covering covered over the wet atmospheric deposition collection buckets and rotated to collect the dry atmospheric deposition. Meanwhile, the TE525 tipping bucket gauge (Texas Electronics, USA) which was anchored $0.7 \mathrm{~m}$ above the ground was used to monitor precipitation. In this study, the method of Balestrini et al. [31] was used for sample collection. According to national atmospheric environmental monitoring criterions, the solution of ethylene glycol was used at the surface of collection bucket to collect the dry atmospheric deposition samples.

The dry atmospheric deposition samples were collected monthly and wet atmospheric deposition samples were collected after each precipitation event. In the monitoring period, the surface soils $(0-10 \mathrm{~cm})$ in atmospheric deposition monitoring sites were collected monthly.

2.3. Analytical Procedures. The wet and dry deposition samples were taken to the laboratory for chemical analysis. The water-soluble ions $\left(\mathrm{Na}^{+}, \mathrm{K}^{+}, \mathrm{Ca}^{2+}, \mathrm{Mg}^{2+}, \mathrm{NH}_{4}{ }^{+}, \mathrm{Cl}^{-}, \mathrm{NO}_{3}{ }^{-}\right.$, and $\mathrm{SO}_{4}{ }^{2-}$ ) were measured by ICS3000 ion chromatograph (Dionex, USA). Total inorganic nitrogen (TIN) was considered as the sum of ammonium nitrogen $\left(\mathrm{NH}_{4}{ }^{+}-\mathrm{N}\right)$ and nitrate nitrogen $\left(\mathrm{NO}_{3}{ }^{-}-\mathrm{N}\right)$. The number of ions and nitrogen content per unit area for wet and dry deposition samples was calculated using cross-sectional area and volume of wet and dry atmospheric deposition collection buckets.

The air-dried soil samples which collected in monitoring sites were extracted in $2 \mathrm{~mol} / \mathrm{L} \mathrm{KCl}$. Then the contents of $\mathrm{NH}_{4}{ }^{+}-\mathrm{N}$ and $\mathrm{NO}_{3}{ }^{-}-\mathrm{N}$ were analyzed by a flow-injection autoanalyzer (Seal-Branlubbe AA3, Seal Germany). The soil volume weight was measured by cutting ring method.

2.4. Statistic Analyses. The data were statistically analyzed by the descriptive statistics and personal correlation coefficient. The significance was defined if the probability value $(P)$ of a test is less than 0.05 .

\section{Results and Discussion}

\subsection{Results}

3.1.1. Ionic Composition and Ion Concentrations in Atmospheric Deposition. The major cations and anions of ionic compositions were $\mathrm{Na}^{+}$and $\mathrm{SO}_{4}{ }^{2-}$ in dry and wet atmospheric deposition in the YRD, respectively (Figure 2). The predominant cation in dry atmospheric deposition was $\mathrm{Na}^{+}$ (71.34\%), followed by $\mathrm{Ca}^{2+}(16.24 \%)$ and $\mathrm{NH}_{4}{ }^{+}$(9.29\%). These three cations accounted for more than $95 \%$ of the total cations in dry atmospheric deposition, while the total number of $\mathrm{K}^{+}$and $\mathrm{Mg}^{2+}$ was less than $5 \%$. The major anions in dry atmospheric deposition were $\mathrm{SO}_{4}{ }^{2-}$ and $\mathrm{NO}_{3}{ }^{-}$, which were more than $93 \%$ of the number of the total anions (Figure 2(a)). Ionic composition in wet atmospheric deposition was similar to that in dry deposition. Compared to the dry atmospheric deposition, the proportions of $\mathrm{Ca}^{2+}$ $(30.42 \%)$ and $\mathrm{NH}_{4}{ }^{+}(14.26 \%)$ in wet atmospheric deposition were relative high. $\mathrm{SO}_{4}{ }^{2-}$ constituted $\sim 77.86 \%$ of the total cation numbers and was also the predominant anion in wet atmospheric deposition (Figure 2(b)).

The significant relations of the total number of anions and the total number of cations were observed in both dry atmospheric depositions $(P<0.005)$ and wet atmospheric depositions $(P<0.0001)$ (Figure 2$)$. The correlation coefficients $\left(R^{2}\right)$ were 0.86 and 0.80 , respectively.

\subsubsection{Monthly Variations of Atmospheric Nitrogen Depositions.}

The main type of nitrogen in dry deposition was $\mathrm{NO}_{3}{ }^{-}-$ $\mathrm{N}(\sim 57.21 \%)$. The maximum values of TIN and $\mathrm{NO}_{3}{ }^{-}-$ $\mathrm{N}$ in dry atmospheric deposition were $139.99 \mathrm{mg} \mathrm{m}^{-2}$ and $113.89 \mathrm{mg} \mathrm{m}^{-2}$, respectively, which was observed in May (Table 1 and Figure 3(a)). The main nitrogen in wet deposition was $\mathrm{NH}_{4}{ }^{+}-\mathrm{N}$ which accounted for $\sim 56.51 \%$. The high content of $\mathrm{NH}_{4}{ }^{+}-\mathrm{N}$ in wet deposition was observed from June to August when the rainfall was abundant (Figure 3(b)). There was a significant positive relationship between the content of $\mathrm{NH}_{4}{ }^{+}-\mathrm{N}$ in wet deposition and precipitation in the study $\left(R^{2}=0.90\right)$. In addition, the fertilizer was widely used in this period. High temperature accelerated ammonia volatilization in wetland ecosystem and large quantity ammonia application caused the content of $\mathrm{NH}_{4}^{+}-\mathrm{N}$ to increase. Therefore the peaks of precipitation $(\sim 297.3 \mathrm{~mm})$ and the content of $\mathrm{NH}_{4}{ }^{+}-\mathrm{N}\left(452.24 \mathrm{mg} \mathrm{m}^{-2}\right)$ in wet deposition occurred simultaneously in August (Figure 3(b)). However the content of $\mathrm{NO}_{3}{ }^{-}-\mathrm{N}$ in wet deposition varied with precipitation was not obvious. During the study period, the contributions of $\mathrm{NO}_{3}{ }^{-}-\mathrm{N}$ and that of $\mathrm{NH}_{4}{ }^{+}-\mathrm{N}$ to total atmospheric deposition were $\sim 48 \%$ and $\sim 52 \%$, respectively (Table 1 ).

The dry and wet atmospheric nitrogen depositions were $\sim 32 \%$ and $\sim 68 \%$ of the total atmospheric nitrogen deposition, respectively (Table 1). The content of nitrogen in dry deposition was the highest in May when the wind was strong in spring in the YRD. With the precipitation increasing and wind becoming weak in summer, the proportion of wet nitrogen deposition increased (Figure 4). When the peak of precipitation occurred in August, the content of wet nitrogen deposition achieved the maximum value $\left(675.64 \mathrm{mg} \mathrm{m}^{-2}\right)$, of which the contribution reached $85.88 \%$. With the precipitation decreasing dramatically from September, contribution of wet nitrogen deposition to the total atmospheric nitrogen deposition gradually declined (Figure 4). Further analysis revealed that there was significant positive relationship between nitrogen content in wet deposition and the precipitation $\left(R^{2}=0.82\right)$ (Figure 5).

3.1.3. Contribution of Atmospheric Deposition for Soil Nitrogen. The average contents of $\mathrm{NO}_{3}{ }^{-}-\mathrm{N}$ and $\mathrm{NH}_{4}{ }^{+}-\mathrm{N}$ in topsoil $(0-10 \mathrm{~cm})$ were $493.49 \mathrm{mg} \mathrm{m}^{-2}$ and $822.36 \mathrm{mg} \mathrm{m}^{-2}$, respectively (Table 2 ). The attribution rates of atmospheric 
TABLE 1: The monthly variation of atmospheric nitrogen deposition.

\begin{tabular}{|c|c|c|c|c|c|c|c|c|c|}
\hline \multirow{2}{*}{ Month } & \multicolumn{2}{|c|}{ Dry deposition } & \multicolumn{2}{|c|}{ Wet deposition } & \multicolumn{2}{|c|}{$\mathrm{NO}_{3}{ }^{-}-\mathrm{N}$} & \multicolumn{2}{|c|}{$\mathrm{NH}_{4}^{+}-\mathrm{N}$} & \multirow{2}{*}{$\operatorname{TIN}\left(\mathrm{mg} \mathrm{m}^{-2}\right)$} \\
\hline & $\begin{array}{c}\begin{array}{l}\mathrm{N} \text { content } \\
\left(\mathrm{mg} \mathrm{m}^{-2}\right)\end{array} \\
\end{array}$ & $\%$ of TIN & $\begin{array}{l}\begin{array}{l}N \text { content } \\
\left(\mathrm{mg} \mathrm{m}^{-2}\right)\end{array} \\
\end{array}$ & $\%$ of TIN & $\begin{array}{c}\text { Content } \\
\left(\mathrm{mg} \mathrm{m}^{-2}\right)\end{array}$ & $\%$ of TIN & $\begin{array}{c}\text { Content } \\
\left(\mathrm{mg} \mathrm{m}^{-2}\right)\end{array}$ & $\%$ of TIN & \\
\hline May & 139.99 & 53.68 & 120.79 & 46.32 & 178.55 & 68.47 & 82.23 & 31.53 & 260.78 \\
\hline Jun. & 103.62 & 27.39 & 274.77 & 72.61 & 242.70 & 64.14 & 135.69 & 35.86 & 378.39 \\
\hline Jul. & 119.84 & 30.04 & 279.03 & 69.96 & 175.42 & 43.98 & 223.44 & 56.02 & 398.87 \\
\hline Aug. & 111.12 & 14.12 & 675.64 & 85.88 & 280.22 & 35.62 & 506.54 & 64.38 & 786.76 \\
\hline Sep. & 77.70 & 41.99 & 107.34 & 58.01 & 97.72 & 52.81 & 87.32 & 47.19 & 185.03 \\
\hline Oct. & 91.66 & 60.89 & 58.88 & 39.11 & 77.15 & 51.25 & 73.38 & 48.75 & 150.54 \\
\hline Nov. & 81.00 & 77.98 & 22.88 & 22.02 & 32.37 & 31.17 & 71.50 & 68.83 & 103.87 \\
\hline Total & 724.92 & 32.02 & 1539.32 & 67.98 & 1084.13 & 47.88 & 1180.11 & 52.12 & 2264.24 \\
\hline
\end{tabular}
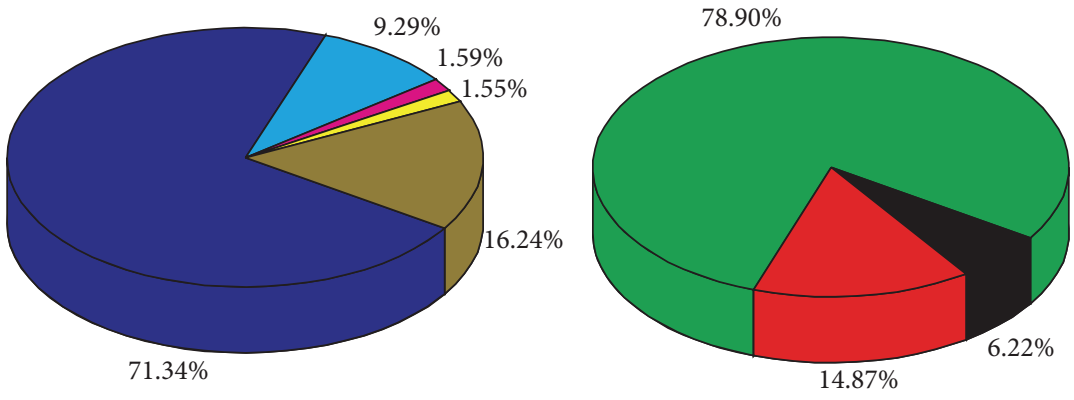

(a)

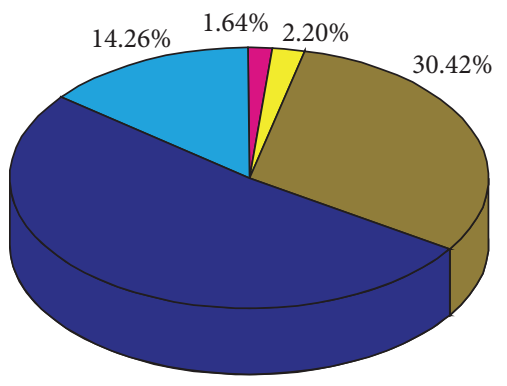

$51.48 \%$

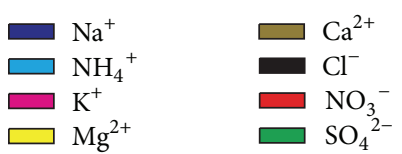

(b)

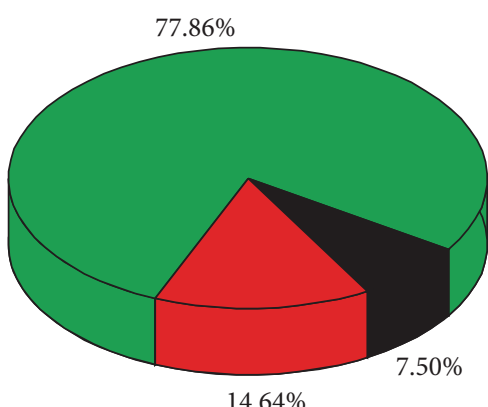

$14.64 \%$
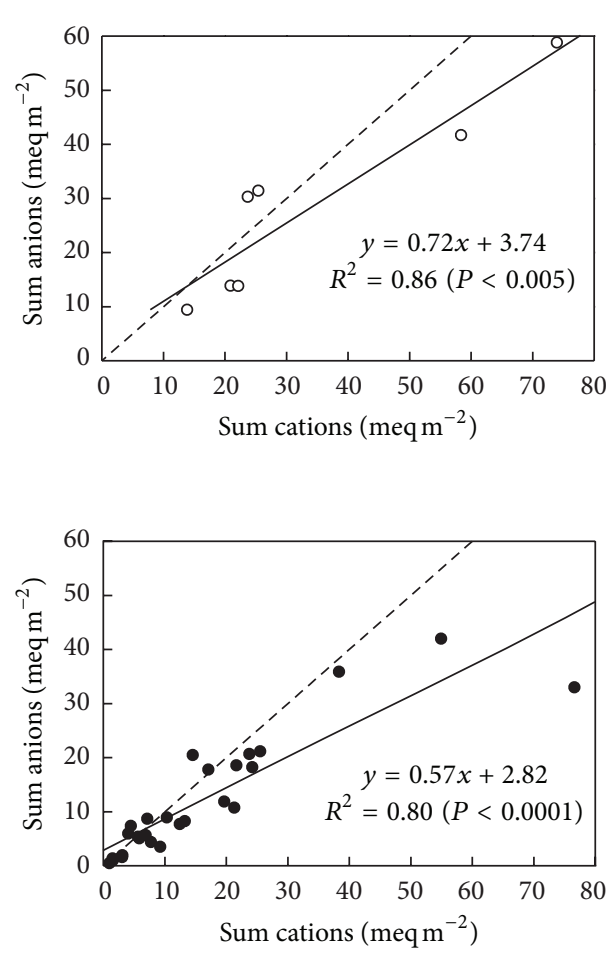

FIGURE 2: The percentage of water-soluble ions and the ionic balance in dry (a) and wet (b) atmospheric deposition.

$\mathrm{NO}_{3}{ }^{-}-\mathrm{N}$ and $\mathrm{NH}_{4}{ }^{+}-\mathrm{N}$ depositions ranged $3.73 \%-80.18 \%$ and $4.77 \%-77.47 \%$, respectively. The maximum of attribution rates of atmospheric $\mathrm{NO}_{3}{ }^{-}-\mathrm{N}$ and $\mathrm{NH}_{4}{ }^{+}-\mathrm{N}$ deposition for that in topsoil both appeared in August $(80.18 \%$ and $77.47 \%$, resp.) (Table 2). The high attribution rates of atmospheric $\mathrm{NO}_{3}{ }^{-}-\mathrm{N}$ deposition for topsoil nitrogen reached $78.04 \%$ in May, while that of $\mathrm{NH}_{4}{ }^{+}-\mathrm{N}$ was the lowest (no more than $5 \%)$. On the contrary, the attribution rates of atmospheric $\mathrm{NO}_{3}{ }^{-}-\mathrm{N}$ deposition for topsoil nitrogen was the lowest in November $(3.73 \%)$, while that of $\mathrm{NH}_{4}{ }^{+}-\mathrm{N}$ reached $20.83 \%$.
The average monthly attribution rates of atmospheric deposition of $\mathrm{NO}_{3}{ }^{-}-\mathrm{N}$ and $\mathrm{NH}_{4}{ }^{+}-\mathrm{N}$ for corresponding nitrogen in $0-10 \mathrm{~cm}$ soil layer in the plant growing season were about $31.38 \%$ and $20.50 \%$, respectively (Table 2 ).

3.2. Discussions. The ionic composition of atmospheric depositions varied in different regions [12, 26, 31]; that is, $\mathrm{Ca}^{2+}$ and $\mathrm{SO}_{4}{ }^{2-}$ were the most abundant cation and anion in urban Beijing [32] and Northern Italy [31]. By contrast, the predominant cation and anion in wet and dry atmospheric 
TABle 2: Atmospheric $\mathrm{N}$ deposition contributes to $\mathrm{N}$ inputs to local soil.

\begin{tabular}{lcccc}
\hline \multirow{2}{*}{ Month } & \multicolumn{2}{c}{ Topsoil } & \multicolumn{2}{c}{ Atmospheric deposition } \\
& $\mathrm{NO}_{3}{ }^{-}-\mathrm{N}\left(\mathrm{mg} \mathrm{m}^{-2}\right)$ & $\mathrm{NO}_{4}{ }^{+}-\mathrm{N}\left(\mathrm{mg} \mathrm{m}^{-2}\right)$ & $\%_{\text {of } \mathrm{NO}_{3}{ }^{+}-\mathrm{N}^{+} \text {content in topsoil }}$ \\
\hline May & 228.78 & 1722.77 & 78.04 & 4.77 \\
Jun. & 706.59 & 976.09 & 34.35 & 13.90 \\
Jul. & 786.59 & 602.23 & 22.30 & 37.10 \\
Aug. & 349.47 & 653.89 & 80.18 & 77.47 \\
Sep. & 281.27 & 816.33 & 34.74 & 10.70 \\
Oct. & 234.77 & 641.91 & 32.86 & 11.43 \\
Nov. & 866.97 & 343.27 & 3.73 & 20.83 \\
\hline Average & 493.49 & 822.36 & 31.38 & 20.50 \\
\hline
\end{tabular}

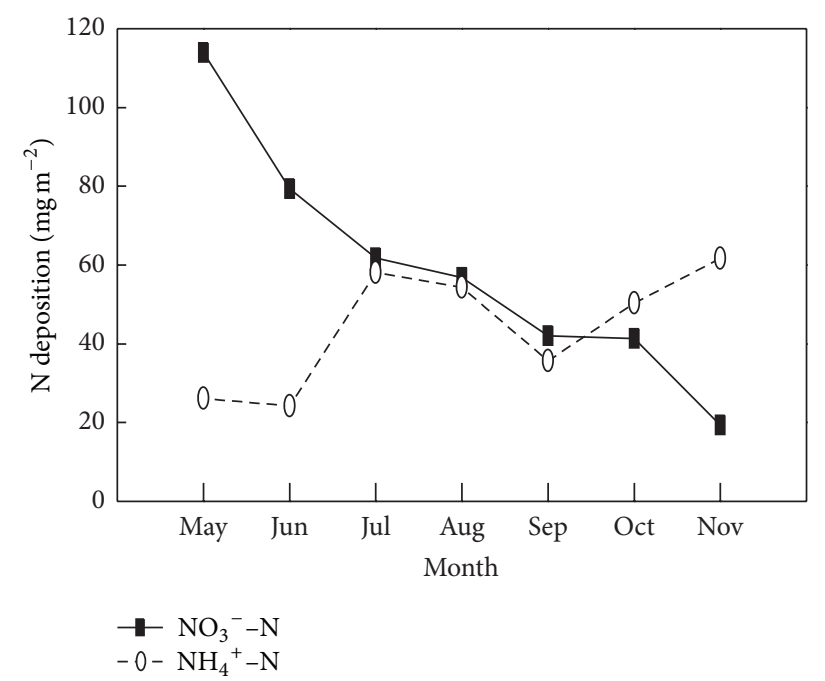

(a)

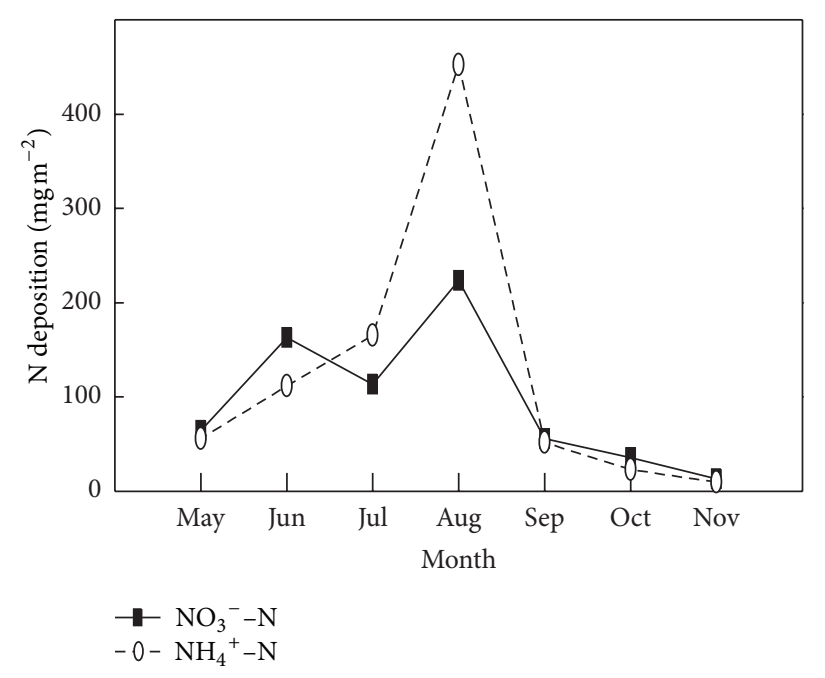

(b)

FIGURE 3: The monthly variations of $\mathrm{NO}_{3}{ }^{-}-\mathrm{N}$ and $\mathrm{NH}_{4}{ }^{+}-\mathrm{N}$ in dry (a) and wet (b) atmospheric depositions.

depositions in the YRD were $\mathrm{Na}^{+}$and $\mathrm{SO}_{4}{ }^{2-}$, respectively (Figure 2). It was closely related to that high salt content in fluvoaquic soil and saline soil which were widely distributed in the YRD $[27,33]$. Our results showed that the most ratios of anions to cations in atmospheric deposition were less than 1 , probably due to some anions such as $\mathrm{F}^{-}, \mathrm{Br}^{-}$and short chain organic anions were not measured in this study $[34,35]$.

The atmospheric nitrogen deposition has been of great concern since 1980s, mainly due to acid rain and its negative effect on ecosystem [36-38]. Previous studies reported that the atmospheric nitrogen deposition only in growing season (2264.24 $\mathrm{mg} \mathrm{N} \mathrm{m}^{-2}$ ) was higher than total nitrogen deposition for the whole year [39]. To agree with that, a large amount of nitrogen deposition was received in coastal zone of the YRD from May to November (Table 1). The wet nitrogen deposition mainly occurred from June to August (Figure 4) because of precipitation (Figure 5). The wet atmospheric nitrogen deposition was more than 2 times of dry atmospheric nitrogen deposition in study region, which was similar with previous results in coastal zone of Barnegat Bay $(>80 \%)$ [40].

Dentener and Crutzen [41] reported that anthropogenic emissions from domestic animals, fertilizer application, and biomass burning were thought to be the largest source of $\mathrm{NH}_{4}{ }^{+}-\mathrm{N}$ in atmospheric deposition. The monthly variations of atmospheric $\mathrm{NH}_{4}{ }^{+}-\mathrm{N}$ deposition results showed that both dry and wet atmospheric $\mathrm{NH}_{4}{ }^{+}-\mathrm{N}$ depositions were high in July and August (Figures 3(a) and 3(b)) when amount of fertilizer is applied for croplands. Another peak dry atmospheric $\mathrm{NH}_{4}{ }^{+}-\mathrm{N}$ deposition appeared in autumn (Figure 3(a)) probably because of the biomass burning in field. The dry atmospheric $\mathrm{NO}_{3}{ }^{-}-\mathrm{N}$ deposition was decreased from spring to autumn and the maximum values (113.89 $\mathrm{mg} \mathrm{m}^{-2}$ ) appeared in May (Figure 3(a)). Its reason is probably that the $\mathrm{NO}_{3}{ }^{-}$ $\mathrm{N}$ of dry atmospheric deposition was strongly influenced by petrochemical industrial pollution which is transferred by wind from Dongying city. However the high $\mathrm{NO}_{3}{ }^{-}-\mathrm{N}$ of wet atmospheric deposition occurring in August (Figure 3(b)) was much related precipitation (Figure 5 ). The similar results were also reported in several studies monitored at similar latitude in China $[22,42]$. The seasonal variation of $\mathrm{NH}_{4}{ }^{+} / \mathrm{NO}_{3}{ }^{-}$ ratio could reflect the deposited nitrogen source [43]. Compared with the developed region, the average $\mathrm{NH}_{4}{ }^{+} / \mathrm{NO}_{3}{ }^{-}$ ratio in atmospheric nitrogen deposition in this study $(\sim 1.16)$ was much less than that in Beijing area and Liaohe River Plain of Northeast China [22, 43] and similar to that in 


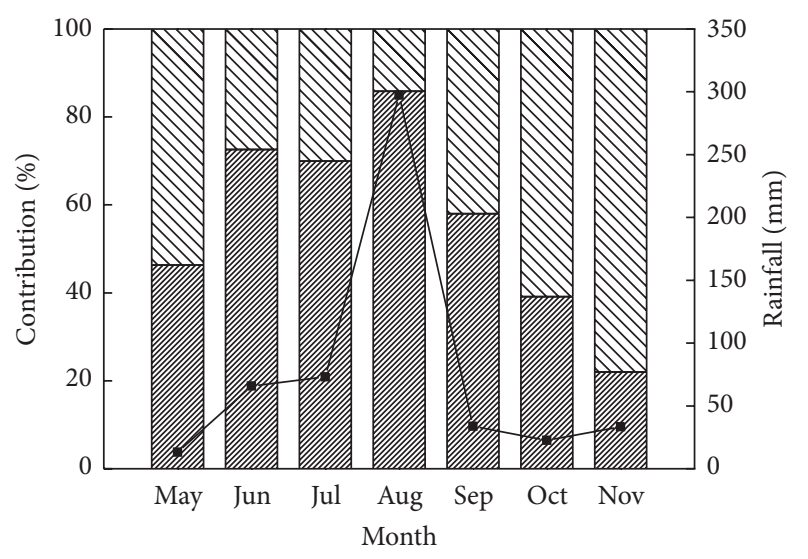

$\square \square$ Dry deposition
שाய Wet deposition
$-\square-$ Rainfall

FIGURE 4: The variation of contributions of wet and dry deposition.

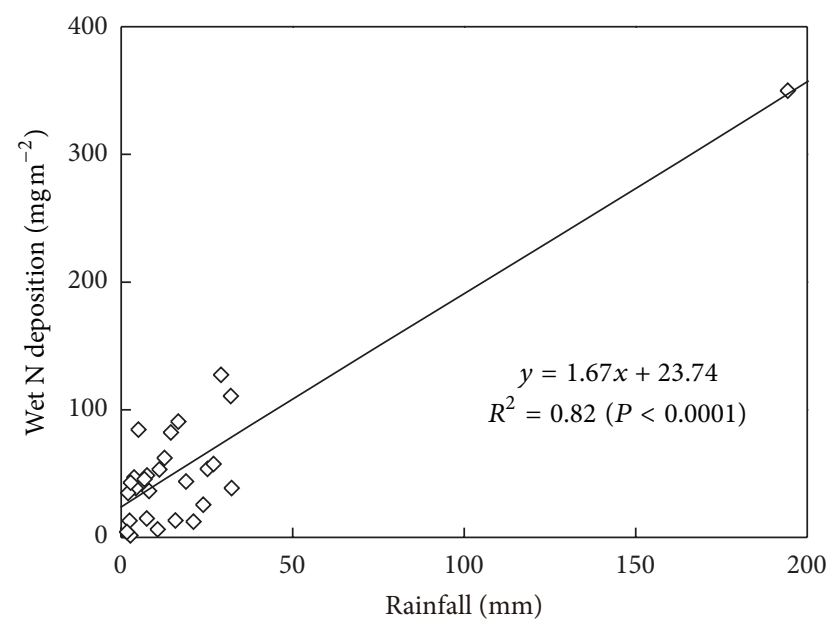

FIGURE 5: Relationship between precipitation and the content of nitrogen in wet deposition.

central New York [44] and Europe [11], suggested that the atmospheric nitrogen deposition in this region was affected by both agricultural activities and industrial activities.

Atmospheric nitrogen deposition has become a large source of nitrogen for terrestrial and aquatic ecosystems worldwide [7]. The total amount of nitrogen deposition and other environment-derived nitrogen in China was up to $18 \mathrm{Tg} \mathrm{N}_{\text {year }}{ }^{-1}$, equal to approximately $60 \%$ of the national nitrogen fertilizer consumption [9]. Atmospheric inputs of bioavailable nitrogen represented an imbalanced contribution to the new production of $8-20 \%$ in the Mediterranean coast of Israel [45]. The average monthly attribution rates of atmospheric deposition of $\mathrm{NO}_{3}{ }^{-}-\mathrm{N}_{\text {and }} \mathrm{NH}_{4}{ }^{+}-\mathrm{N}$ were about $31.38 \%$ and $20.50 \%$ for the contents of $\mathrm{NO}_{3}{ }^{-}-\mathrm{N}$ and $\mathrm{NH}_{4}{ }^{+}-$ $\mathrm{N}$ in $0-10 \mathrm{~cm}$ soil layer, respectively (Table 2 ), suggesting that the atmospheric nitrogen deposition was one of the main sources of soil nitrogen in coastal wetland ecosystem in the YRD.

\section{Conclusions}

The cation of $\mathrm{Na}^{+}$and anion of $\mathrm{SO}_{4}{ }^{2-}$ were major ionic compositions in dry and wet atmospheric deposition in the YRD. There were the significant relations of the total number of anions and the total number of cations in both dry atmospheric depositions $(P<0.005)$ and wet atmospheric depositions $(P<0.0001)$, respectively. The main form of atmospheric nitrogen input was wet deposition which accounted for $67.98 \%$ of the total atmospheric nitrogen deposition. Both dry and wet atmospheric $\mathrm{NH}_{4}{ }^{+}-\mathrm{N}$ depositions were high in July and August. The $\mathrm{NO}_{3}{ }^{-}-\mathrm{N}$ of dry atmospheric deposition was decreased from spring to autumn. There was a significant positive relationship between wet atmospheric nitrogen deposition and precipitation. The average $\mathrm{NH}_{4}{ }^{+} / \mathrm{NO}_{3}{ }^{-}$ ratio in atmospheric nitrogen deposition indicated that the atmospheric nitrogen deposition in this region was affected by both agricultural activities and industrial activities. Our results suggested that the atmospheric nitrogen deposition was one of the main sources of soil nitrogen in coastal wetland ecosystem in the YRD.

\section{Conflict of Interests}

The authors declare that there is no conflict of interests regarding the publication of this paper.

\section{Acknowledgments}

The authors are grateful for the support from the Project of National Science \& Technology Pillar Program in "12th Five Year" period (2011BAC02B01), the National Natural Science Foundation for Distinguished Young Scholar of Shandong Province (no. JQ201114), and the CAS/SAFEA International Partnership Program for Creation Research Team. They thank the Yellow River Delta Ecology Research Station of Coastal Wetland, CAS, for the help of field work.

\section{References}

[1] J. D. Aber, K. J. Nadelhoffer, P. Steudler, and J. M. Melillo, "Nitrogen saturation in northern forest ecosystems," Bioscience, vol. 39, no. 6, pp. 378-386, 1989.

[2] N. J. P. Owens, J. N. Galloway, and R. A. Duce, "Episodic atmospheric nitrogen deposition to oligotrophic oceans," Nature, vol. 357, no. 6377, pp. 397-399, 1992.

[3] R. Bobbink, M. Hornung, and J. G. M. Roelofs, "The effects of air-borne nitrogen pollutants on species diversity in natural and semi-natural European vegetation," Journal of Ecology, vol. 86, no. 5, pp. 717-738, 1998.

[4] S. V. Krupa, "Effects of atmospheric ammonia (NH3) on terrestrial vegetation: a review," Environmental Pollution, vol. 124, no. 2, pp. 179-221, 2003.

[5] R. A. Duce, J. LaRoche, K. Altieri et al., "Impacts of atmospheric anthropogenic nitrogen on the open ocean," Science, vol. 320, no. 5878, pp. 893-897, 2008.

[6] N. Gruber and J. N. Galloway, "An Earth-system perspective of the global nitrogen cycle," Nature, vol. 451, no. 7176, pp. 293296, 2008. 
[7] J. N. Galloway, A. R. Townsend, J. W. Erisman et al., "Transformation of the nitrogen cycle: Recent trends, questions, and potential solutions," Science, vol. 320 , no. 5878, pp. 889-892, 2008.

[8] P. A. Matson, W. H. McDowell, A. R. Townsend, and P. M. Vitousek, "The globalization of $\mathrm{N}$ deposition: ecosystem consequences in tropical environments," Biogeochemistry, vol. 46, no. 1-3, pp. 67-83, 1999.

[9] X. Liu, L. Song, C. He, and F. Zhang, "Nitrogen deposition as an important nutrient from the environment and its impact on ecosystems in China," Journal of Arid Land, vol. 2, no. 2, pp. 137$143,2010$.

[10] Q. G. Wang, S. B. Li, P. Jia, C. J. Qi, and F. Ding, "A review of surface water quality models," Scientific World Journal, vol. 2013, Article ID 231768, 7 pages, 2013.

[11] K. W. T. Goulding, N. J. Bailey, N. J. Bradbury et al., "Nitrogen deposition and its contribution to nitrogen cycling and associated soil processes," New Phytologist, vol. 139, no. 1, pp. 49-58, 1998.

[12] W. A. H. Asman, M. A. Sutton, and J. K. Schjørring, "Ammonia: emission, atmospheric transport and deposition," New Phytologist, vol. 139, no. 1, pp. 27-48, 1998.

[13] M. Griepentrog, S. Bode, P. Boeckx, F. Hagedorn, A. Heim, and M. W. I. Schmidt, "Nitrogen deposition promotes the production of new fungal residues but retards the decomposition of old residues in forest soil fractions," Global Change Biology, vol. 20, no. 1, pp. 327-340, 2014.

[14] J. B. Wang, T. C. Zhu, H. W. Ni, H. X. Zhong, X. L. Fu, and J. F. Wang, "Effects of elevated $\mathrm{CO}_{2}$ and nitrogen deposition on ecosystem carbon fluxes on the sanjiang plain wetland in Northeast China," PLoS ONE, vol. 8, no. 6, 2013.

[15] W. Schroder, R. Pesch, S. Schonrock, H. Harmens, G. Mills, and H. Fagerli, "Mapping correlations between nitrogen concentrations in atmospheric deposition and mosses for natural landscapes in Europe," Ecological Indicators, vol. 36, pp. 563571, 2014.

[16] N. B. Dise and R. F. Wright, "Nitrogen leaching from European forests in relation to nitrogen deposition," Forest Ecology and Management, vol. 71, no. 1-2, pp. 153-161, 1995.

[17] T. Endo, H. Yagoh, K. Sato et al., "Regional characteristics of dry deposition of sulfur and nitrogen compounds at EANET sites in Japan from 2003 to 2008," Atmospheric Environment, vol. 45, no. 6, pp. 1259-1267, 2011.

[18] M. E. Fenn, M. A. Poth, J. D. Aber et al., "Nitrogen excess in North American ecosystems: predisposing factors, ecosystem responses, and management strategies," Ecological Applications, vol. 8, no. 3, pp. 706-733, 1998.

[19] Y. Pan, Y. Wang, G. Tang, and D. Wu, "Wet and dry deposition of atmospheric nitrogen at ten sites in Northern China," Atmospheric Chemistry and Physics, vol. 12, no. 14, pp. 65156535, 2012.

[20] J. Cui, J. Zhou, Y. Peng, Y. Q. He, H. Yang, and J. D. Mao, "Atmospheric wet deposition of nitrogen and sulfur to a typical red soil agroecosystem in Southeast China during the ten-year monsoon seasons (2003-2012)," Atmospheric Environment, vol. 82, pp. 121-129, 2014.

[21] D. Lamb and J. van Bowersox, "The national atmospheric deposition program: an overview," Atmospheric Environment, vol. 34, no. 11, pp. 1661-1663, 2000.

[22] X. Liu, X. Ju, Y. Zhang, C. He, J. Kopsch, and Z. Fusuo, "Nitrogen deposition in agroecosystems in the Beijing area," Agriculture, Ecosystems and Environment, vol. 113, no. 1-4, pp. 370-377, 2006.
[23] A. F. Bouwman, L. J. M. Boumans, and N. H. Batjes, "Estimation of global $\mathrm{NH}_{3}$ volatilization loss from synthetic fertilizers and animal manure applied to arable lands and grasslands," Global Biogeochemical Cycles, vol. 16, no. 2, 2002.

[24] D. G. Streets and S. T. Waldhoff, "Present and future emissions of air pollutants in China: $\mathrm{SO}_{2}, \mathrm{NO}_{x}$ and CO," Atmospheric Environment, vol. 34, no. 3, pp. 363-374, 2000.

[25] Y. Jia, G. Yu, N. He et al., "Spatial and decadal variations in inorganic nitrogen wet deposition in China induced by human activity," Scientific Reports, vol. 4, Article ID 3763, 2014.

[26] F. Dentener, J. Drevet, J. F. Lamarque et al., "Nitrogen and sulfur deposition on regional and global scales: a multimodel evaluation," Global Biogeochemical Cycles, vol. 20, no. 4, Article ID GB4003, 2006.

[27] Q. He, B. S. Cui, X. S. Zhao, H. L. Fu, X. Xiong, and G. H. Feng, "Vegetation distribution patterns to the gradients of water depth and soil salinity in wetlands of Yellow River Delta, China," Wetland Science, vol. 5, no. 3, pp. 208-214, 2007.

[28] J. Shen, A. Tang, X. Liu, A. Fangmeier, K. T. W. Goulding, and F. S. Zhang, "High concentrations and dry deposition of reactive nitrogen species at two sites in the North China Plain," Environmental Pollution, vol. 157, no. 11, pp. 3106-3113, 2009.

[29] Y. Zhang, X. J. Liu, A. Fangmeier, K. T. W. Goulding, and F. S. Zhang, "Nitrogen inputs and isotopes in precipitation in the North China Plain," Atmospheric Environment, vol. 42, no. 7, pp. 1436-1448, 2008.

[30] J. Yu, X. Wang, K. Ning et al., "Effects of Salinity and Water Depth on Germination of Phragmites australis in Coastal Wetland of the Yellow River Delta," Clean-Soil Air Water, vol. 40, no. 10, pp. 1154-1158, 2012.

[31] R. Balestrini, L. Galli, and G. Tartari, "Wet and dry atmospheric deposition at prealpine and alpine sites in northern Italy," Atmospheric Environment, vol. 34, no. 9, pp. 1455-1470, 2000.

[32] Y. Y. Cai, F. M. Yang, K. B. He, Y. L. Ma, O. Tomoaki, and T. Shigeru, "Characteristics of water-soluble ions in dry deposition in urban Beijing," China Environmental Science, vol. 31, no. 7, pp. 1071-1076, 2011.

[33] J. Yu, Y. Li, G. Han et al., "The spatial distribution characteristics of soil salinity in coastal zone of the Yellow River Delta," Environmental Earth Sciences, 2013.

[34] F. Zhang, J. Zhang, H. Zhang, N. Ogura, and A. Ushikubo, "Chemical composition of precipitation in a forest area of Chongqing, Southwest China," Water, Air, and Soil Pollution, vol. 90, no. 3-4, pp. 407-415, 1996.

[35] R. Mosello and G. A. Tartari, "Formiate and acetate in wet deposition at Pallanza (NW Italy) in relation to major ion concentrations," Water, Air, and Soil Pollution, vol. 63, no. 3-4, pp. 397-409, 1992.

[36] N. van Breemen and H. F. G. van Dijk, "Ecosystem effects of atmospheric deposition of nitrogen in The Netherlands," Environmental Pollution, vol. 54, no. 3-4, pp. 249-274, 1988.

[37] E. D. Schulze, "Air pollution and forest decline in a spruce (Picea abies) forest," Science, vol. 244, no. 4906, pp. 776-783, 1989.

[38] S. E. Schwartz, "Acid deposition: unraveling a regional phenomenon," Science, vol. 243, no. 4892, pp. 753-763, 1989.

[39] Y. Luo, X. Yang, R. J. Carley, and C. Perkins, "Atmospheric deposition of nitrogen along the Connecticut coastline of Long Island Sound: a decade of measurements," Atmospheric Environment, vol. 36, no. 28, pp. 4517-4528, 2002.

[40] Y. A. Gao, "Atmospheric nitrogen deposition to Barnegat Bay," Atmospheric Environment, vol. 36, no. 38, pp. 5783-5794, 2002. 
[41] F. Dentener and P. J. Crutzen, "A three-dimensional model of the global ammonia cycle," Journal of Atmospheric Chemistry, vol. 19, no. 4, pp. 331-369, 1994.

[42] Z. Fang and X. Zhao, "Dynamic changes of atmospheric nitrogen wet deposition in Qingdao," Journal of Soil and Water Conservation, vol. 27, no. 1, pp. 263-266, 2013.

[43] W. Yu, C. Jiang, Q. Ma, Y. Xu, H. Zou, and S. Zhang, "Observation of the nitrogen deposition in the lower Liaohe River Plain, Northeast China and assessing its ecological risk," Atmospheric Research, vol. 101, no. 1-2, pp. 460-468, 2011.

[44] T. J. Fahey, C. J. Williams, J. N. Rooney-Varga et al., "Nitrogen deposition in and around an intensive agricultural district in central New York," Journal of Environmental Quality, vol. 28, no. 5, pp. 1585-1600, 1999.

[45] B. Herut, M. D. Krom, G. Pan, and R. Mortimer, "Atmospheric input of nitrogen and phosphorus to the Southeast Mediterranean: sources, fluxes, and possible impact," Limnology and Oceanography, vol. 44, no. 7, pp. 1683-1692, 1999. 

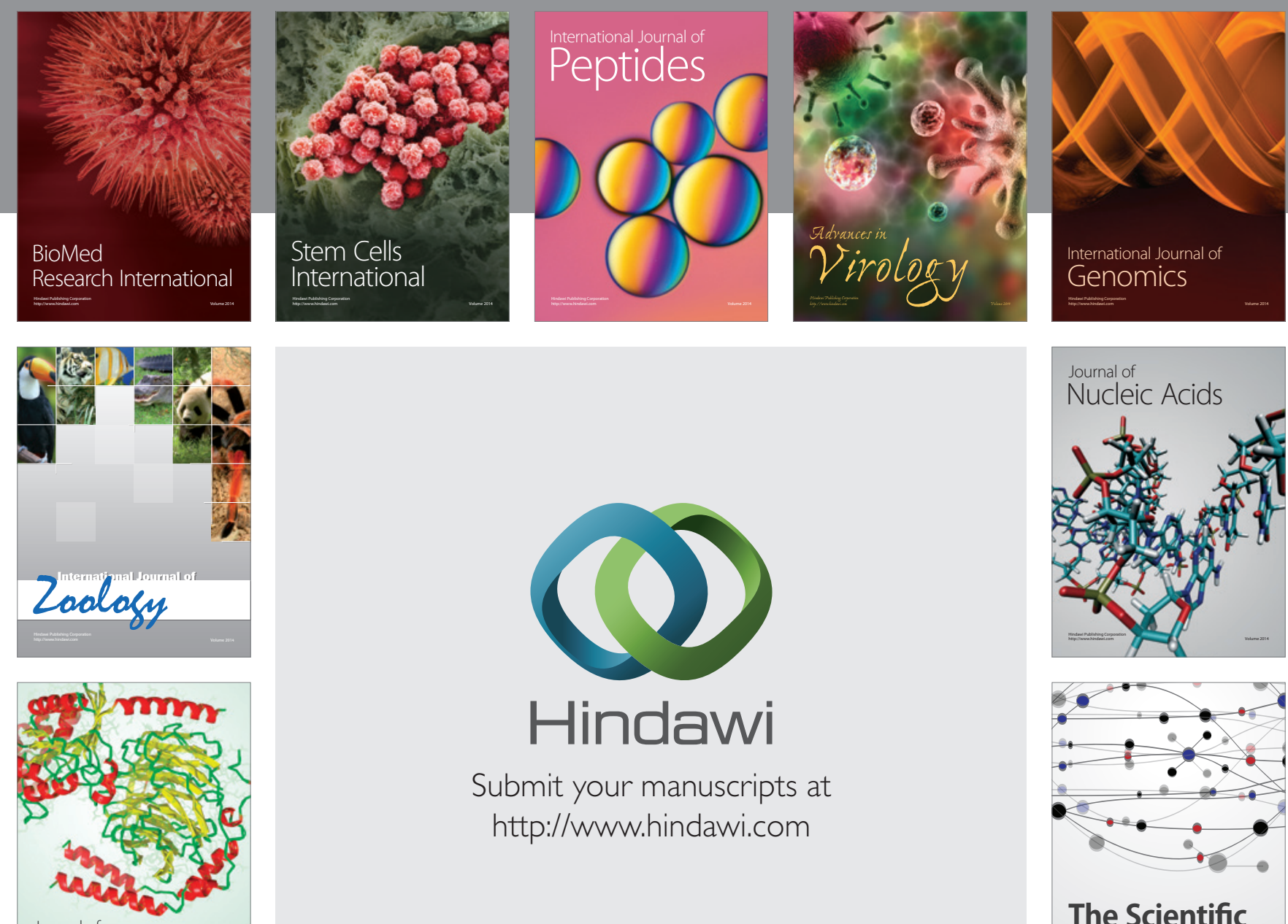

Submit your manuscripts at

http://www.hindawi.com

Journal of
Signal Transduction
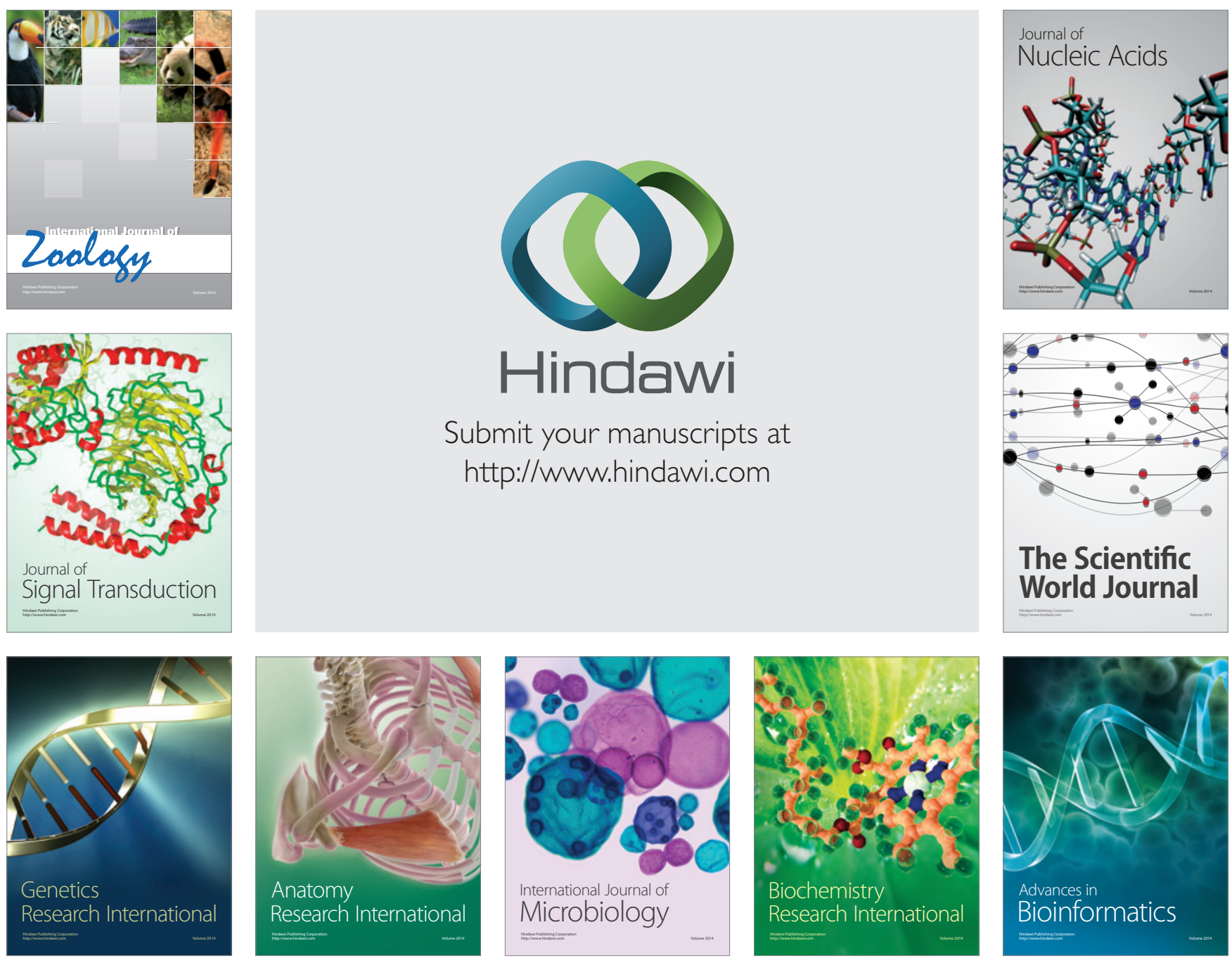

The Scientific World Journal
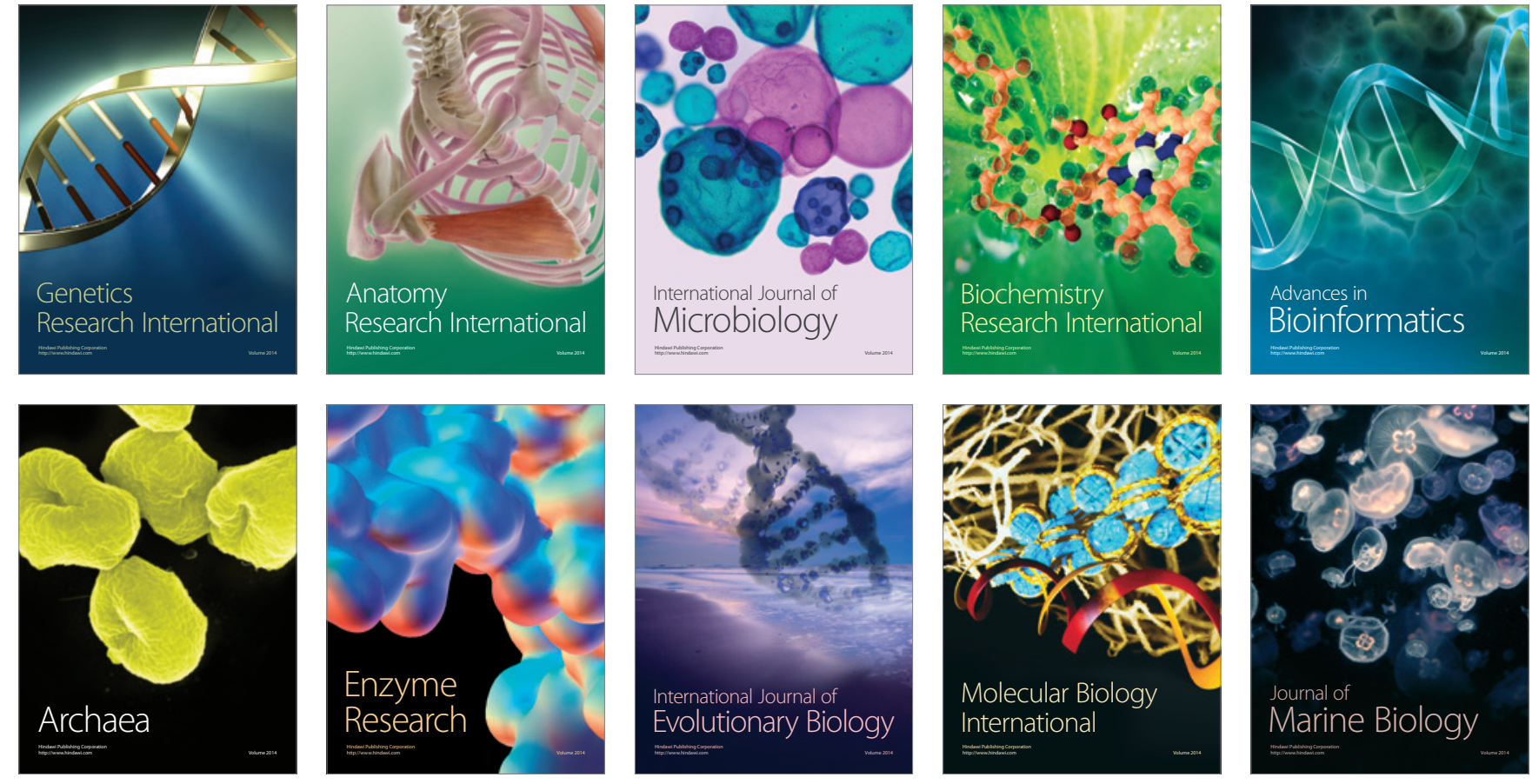